\title{
Geografia urbana e as novas centralidades como subsídio as pesquisas em cidades turísticas
}

\section{Urban geography and the new centralities as support to research in tourist citie}

\author{
Wilson Martins Lopes-Junior
}

\begin{abstract}
RESUMO
Existem diversas mudanças espaciais que ocorrem nas cidades, de acordo com estrutura, processo, função e forma. No caso das localidades turísticas, essas alterações urbanas merecem maior atenção devido à sua complexidade e necessidade do turismo em utilizar os elementos deste espaço. Dentre as mudanças espaciais urbanas estão as referentes às políticas e espaços públicos, à especulação imobiliária, à segregação socioespacial e às novas centralidades urbanas. É no surgimento destas que ocorre uma dinâmica contraditória de concentração e descentralização dos espaços urbanos, redefinindo as relações centro-periferia. Nesta perspectiva, o tecido urbano é reorganizado e fragmentado junto às novas localizações das empresas de comércio e serviços, como as de turismo. O resultado é o surgimento de espaços internos de produção, moradia e de consumo que alteram o valor destas áreas, criando centros com funções distintas que contribuem na segregação socioespacial. No contexto de turismo e urbanização, este ensaio, sustentando-se no conhecimento teórico da geografia urbana, propõe-se a auxiliar as pesquisas de turismo urbano, através da discussão a respeito das novas centralidades urbanas.
\end{abstract}

PALAVRAS-CHAVE: Turismo e Urbanização; Turismo e Espaço Urbano; Novas Centralidades.

\section{ABSTRACT}

There are various spatial changes that occur on the cities, according to structure, process, function and form. In the case of the tourist locations, these urban changes deserve greater attention due to its complexity and tourism's necessity of use of elements of the space. Among the urban spatial changes are those related to public policy and spaces, real estate speculation, the socio-spatial segregation and the new urban centralities. It is on the emergence of these, that happens one contradictory dynamics of concentration and decentralization of urban, redefining center-periphery relations. In this perspective, the urban contexture is rearranged and fragmented along the new localizations of trade and services companies, like the tourism ones. The result is the rise of internal spaces of production, housing and consumption that alter the value of these areas, creating centers with different functions that contribute to the socio-spatial segregation. In the context of tourism and urbanization, this assay, based on urban geography's theoretical knowledge, proposes to help the researches on urban tourism through the discussion of the new urban centralities.

KEYWORDS: Tourism and Urbanization; Tourism and Urban Spaces; New Centralities. 


\section{Introdução}

O turismo é estritamente relacionado com o espaço geográfico, uma vez que esta atividade cria e recria diferentes formas espaciais em seu processo de estruturação. Dessa forma, o espaço geográfico é transformado e (re)organizado conforme a lógica do turismo. Sendo assim, este associa-se ao espaço e utiliza-se de outros setores e do poder público para modelar e reconstruir localidades atrativas aos turistas, estabelecendo a atividade.

Nesta perspectiva, de acordo com Coriolano (1998), o turismo se destaca como um agente que provoca alterações no espaço geográfico, posto que se desenvolve por meio dos elementos deste.

A partir dessas alterações desenvolve-se a produção do espaço turístico. Nele, as relações entre os sistemas de objetos e de ações sob a lógica capitalista, determinam a mercantilização do espaço a ser consumido, segundo Carlos (2002). Sendo assim, conclui-se que o referido espaço turístico é o resultado da apropriação dos elementos presentes no espaço geográfico pelo turismo, acrescidos de valor, de modo a constituir-se no produto turístico a ser consumido. No espaço urbano, as questões referentes ao consumo do espaço pelo turismo são mais explícitas, devido à alta concentração dos elementos necessários para esta atividade, como a infraestrutura de suporte.

Inúmeras alterações ocorrem no espaço urbano devido a fatores globais e locais, nos quais o turismo também é relevante. No caso das cidades, as quais tem o turismo como uma das principais atividades econômicas, coexistem turistas e moradores compartilhando suas infraestruturas e equipamentos públicos. Por outro lado, também há infraestruturas e equipamentos específicos que servem somente aos turistas. Dessa forma, é a cidade, construção física e imaginária do espaço urbano, que, historicamente, se destaca pela atração de grandes contingentes de turistas, o que, por sua vez, resulta em alterações significativas no espaço urbano.

Autor expressivo nesta discussão do espaço urbano, especificamente na relação turismo e território, é Knafou (1996), que identifica três situações particulares de relação entre o turismo e a cidade. Para o referido autor, o turismo pode ocorrer antecedendo o espaço urbano, sendo posterior ao espaço urbano, ou, ainda, pode ser simultâneo ao desenvolvimento do espaço urbano.

É preciso explicitar que o entendimento de urbanização do presente artigo é constituído de um processo, cuja materialização é dada no espaço urbano, componente da cidade. Uma vez que a cidade é dotada de um tecido que não é estático, mas mutável em suas novas formas e funções.

As mudanças espaciais ocorridas na cidade são muitas, e quando se trata de uma localidade turística, dada a sua singularidade, merecem especial atenção. Dentre essas mudanças, estão as referentes à especulação imobiliária, às políticas e espaços públicos, à segregação socioespacial e às novas centralidades. 


\section{Centro - periferia e as novas centralidades}

Os elementos que configuram o espaço urbano e a sua reestruturação permitem a análise da concentração das atividades e das pessoas no próprio espaço, ou seja, a compreensão sobre as transformações nas formas da centralidade. Assim, o espaço torna-se reflexo da sociedade, produto social decorrente do acumulo de ações históricas de atores que produzem e também consomem o próprio espaço, fragmentado e articulado.

O espaço urbano capitalista - fragmentado, articulado, reflexo, condicionante social, cheio de símbolos e campo de lutas - é um produto social, resultado de ações acumuladas através do tempo, e engendradas por agentes que produzem e consomem o espaço (CORRÊA, 1995, p.11).

O espaço urbano, portanto, com suas diferentes características, é um produto social e não somente reflexo da sociedade. Ele se constitui na própria sociedade, alimentando-a com as suas constantes alterações e garantindo a existência da sociedade.

É justamente a partir de sua reprodução (produção - consumo), que o espaço urbano sofre alterações em sua forma. Cabe aqui resgatar que é nas cidades que há a concentração espacial dos meios de produção, o que possibilita o espaço de consumo. Assim, tanto a produção como o consumo ocorrem na cidade, ou seja, ela se comporta como o espaço simultâneo dessas ações.

Nota-se que o modo de produção capitalista exerce forças desigualmente distribuídas pelo tecido urbano, criando articulações e fragmentações. Por conta disso, o espaço urbano possui assimetrias consolidadas nas relações centro-periferia. Estas, por sua vez, não são cristalizadas de forma imutável no espaço urbano, sendo flexíveis e passíveis dos processos de descentralização e recentralização, formando assim as novas centralidades.

Sobre o entendimento da formação de novas centralidades deve-se considerar a questão centro - periferia decorrente da alteração na configuração espacial urbana, como na dinâmica da cidade. Isso porque na dinâmica do desenvolvimento desta, existem os elementos que configuram a produção do espaço urbano e a sua reestruturação, num processo que evidencia as áreas de concentração do espaço urbano, ou seja, a centralidade. Merece ênfase o fato de que o deslocamento geográfico espacial decorre de decisões de gestores empresariais, inclusive o poder publico, que provocam novas localizações de diferentes empresas, influindo diretamente na relação centro - periferia.

Neste contexto apresentam-se as mudanças espaciais da cidade, relacionadas às áreas de atividades comerciais e de serviços, como as do turismo, que apresentam a descontinuidade, bem como também novos espaços fragmentados sustentados na relação centro - periferia.

Esta relação, por sua vez, é essencial na compreensão das novas centralidades. Isso ocorre devido à morfologia urbana ser alterada 
justamente diante da definição das novas centralidades e a formação de outras periferias. A cidade, portanto, através de seu tecido urbano, expõe uma dinâmica contraditória de concentração e de descentralização dos espaços urbanos, em constante redefinição do par centro-periferia, que resulta nas novas centralidades.

\begin{abstract}
É a natureza dessa trama urbana distendida de densidades múltiplas - que combina concentração com descentralização, localizações com fluxos, imóveis com acelerados e diversos ritmos de mobilidade no interior dos espaços urbanos - que redefine o par centro-periferia, a partir da constatação de que há várias centralidades em definição e diferentes periferias em constituição (SPÓSITO, 2001, p.89).
\end{abstract}

Nesta perspectiva, as novas estratégias econômicas e de localização de grandes grupos econômicos comerciais e de serviços, como também os de turismo, interferem diretamente na estrutura urbana, alterando as relações do centro com o seu entorno e com as suas áreas periféricas. Portanto, a concentração e descentralização que ocorre no espaço urbano refletem em nova dinâmica no espaço intraurbano, apresentando novas centralidades atreladas às novas localizações de grupos, empresas de comércio e de serviços, favorecendo a fragmentação espacial, o que demonstra uma nova dinâmica.

No caso do turismo, essa questão relaciona-se a localização (implantação) de objetos turísticos como hotéis, resorts, espaços para eventos, e outros empreendimentos urbanos que reforçam as centralidades, ou, ainda, criam novas centralidades associadas à especulação imobiliária. Comumente, no espaço urbano, as atividades turísticas tendem a concentrar-se em partes específicas do tecido urbano. Ou seja, há o uso de espaços específicos onde concentram-se os atrativos turísticos, sejam estes históricos, culturais, religiosos, de consumo, entre outros, que justificam o deslocamento dos turistas. Esses centros turísticos nas cidades oferecem inúmeros serviços, e exprimem uma identidade singular a partir dos usos do solo destinados ao turismo.

Deste modo, as dinâmicas do espaço urbano são essenciais à pratica do turismo, assim como significativas para o seu entendimento e planejamento. Vale ainda mencionar que o entendimento dessa dinâmica espacial das cidades pode colaborar com a discussão acerca do turismo urbano, em suas dimensões temporais e espaciais.

\title{
Novas centralidades e o turismo
}

$\mathrm{Na}$ dinâmica espacial urbana as novas centralidades expõem a morfologia urbana, que expressa as desigualdades socioespaciais. Deste modo, é na relação entre concentração - descentralização que se produzem essas novas centralidades, através da redefinição centro-periferia, que é explicitada na fragmentação do espaço urbano. Diante dessa dinâmica, percebe-se uma nova forma urbana, dada à cidade a partir do processo de desconcentração. 
O termo desconcentração, segundo Gottdiener (1993), é adequado para compreender a situação de desenvolvimento que está diretamente relacionada à descentralização e concentração nas cidades. O autor avalia que a desconcentração constitui-se numa forma e também num processo que representa a dialética dos aspectos sociais e espaciais. Ainda sobre as cidades, Gottdiener (1993) identifica o surgimento de vários outros centros urbanos decorrentes do crescimento das periferias, o que o referido autor, chama de "crescimento polinucleado". Outra autora que também trata desta mesma temática é Spósito (2007) atribuindo, todavia, outra denominação: "desconcentração concentrada".

Essas teorias compreendem também as diferentes mudanças da forma urbana, que são notadas no próprio espaço urbano, sendo que, são algumas as dinâmicas responsáveis pelas alterações do espaço urbano. Neste sentido, Spósito (2001) identifica dinâmicas importantes a partir do impacto que ocasionam na estrutura do espaço urbano.

a. Nova lógica das indústrias com relação ao espaço (flexibilização do uso do espaço), através da diminuição das plantas industriais e separação entre gestão e produção, esta última concentrando-se na periferia;

b. Nova configuração do habitat urbano e diferentes formas de assentamentos humanos. Instalação de conjuntos habitacionais na periferia de metrópoles, grandes e médias cidades para população de baixo poder aquisitivo. Para população de classe média e alta, os villages, que divulgam a qualidade de vida, localizando-se fora e dentro das áreas urbanas. Além disso, também há as cidades satélites, a exemplo de Brasília, nas quais a função socioeconômica está atrelada ao planejamento urbano;

c. Novas localizações de equipamentos de consumo e prestação de serviços (shoppings-centers, hipermercados, centros empresariais, outros), que geralmente se instalam em áreas antes não loteadas, reforçando, assim, a produção de novas centralidades ou a polinucleação.

No caso da dinâmica da flexibilidade de localização das indústrias, tem-se o surgimento de novas aglomerações, ou de outras centralidades, decorrentes da linha de produção transferida para a periferia, o que atrai outros serviços a ela associados, como as empresas de sustentação manutenção. Neste sentido, se inicia uma nova aglomeração, redefinindo a centralidade, inclusive em relação aos bairros residenciais, posto que há necessidade de moradias para a força de trabalho que se concentrará nesses novos centros.

Ao que se refere à formação dos novos assentamentos humanos, como núcleos habitacionais e condomínios fechados em setores distantes do centro, destaca-se a questão do poder público através do planejamento urbano. Ocorre que a instalação destes assentamentos urbanos em áreas distantes necessita de altos investimentos públicos em infraestrutura, como vias de circulação e transporte. Também há 0 favorecimento da 
especulação imobiliária, uma vez que a formação desses novos assentamentos em geral não é contínua.

Ainda neste caso, pode-se incluir a formação de áreas residenciais voltadas à população turística, como os condomínios fechados e segundas residências que, além de necessitarem de infraestrutura de suporte, favorecem a segregação socioespacial e a especulação imobiliária nas localidades turísticas. A questão da especulação imobiliária presente nas cidades turísticas que, inclusive, causa a própria segmentação dos espaços, se relaciona a existência do turismo imobiliário.

\begin{abstract}
O turismo imobiliário é uma nova forma que o mercado imobiliário encontra para reestruturar-se, sem depender, diretamente, do financiamento público e sem depender das especificidades da economia local, isto é, da renda local. Essa modalidade de produção imobiliária está relacionada com a segmentação dos espaços (em práticas de lazer, ócio, descanso, alimentação etc.) e a possibilidade de novos capitais, advindos de investidores externos, sejam estes grupos ou indivíduos (SILVA; FERREIRA, apud VALENÇA; CAVALCANTE, 2007)
\end{abstract}

Sobre os equipamentos de consumo e serviços, como shoppingscenters, hipermercados, incluindo os voltados ao turismo, a questão do planejamento urbano torna-se essencial, devido à necessidade de infraestrutura. Em cidades turísticas, estes equipamentos geralmente estão localizados nos próprios lugares turísticos e são voltados a atenderem, em parte, as necessidades dos turistas, ou seja, oferecer produtos de acordo com as exigências trazidas pelo turista do local emissor. Neste sentido, o lugar turístico apresenta-se como uma representação urbana dos desejos do turista.

A Riviera de São Lourenço é, também, um simulacro, considerando-se o fato de que busca copiar, reproduzir aspectos desejados da vida na metrópole, tais como seu urbanismo e serviços. O maior e mais movimentado shopping center de Bertioga, por exemplo, está na Riviera de São Lourenço. Acrescentam-se a essas características qualidades difíceis a serem encontradas por quem vive numa cidade de um país pobre, ou seja, segurança $24 \mathrm{~h}$ por dia e oportunidades de lazer ao seu lado (CRUZ apud CRUZ, 2007, p.21).

Para Luchiari (1998, p.23), os lugares turísticos possuem uma organização territorial que se mostra como uma "(...) reprodução de atributos valorizados nos centros urbanos emissores, (...)". Nota-se, portanto, um choque de culturas e de representações no próprio tecido urbano, de acordo com os empreendimentos turísticos e suas funções. Essa questão provoca discussões importantes acerca da relação cultural entre os turistas, com suas particularidades provenientes do local emissor, e a população local receptora. 
Nesse contexto do surgimento de uma nova configuração do tecido urbano, representado através dos diferentes loteamentos, conjuntos habitacionais, equipamentos de comércio e prestação de serviços, como shoppings-centers, hipermercados e centros de lazer, evidenciam-se as novas centralidades na morfologia urbana. Portanto, a instalação de equipamentos comerciais e de serviços são os responsáveis pela intensa expansão do tecido urbano descontínuo numa estruturação polinucleada, o que torna impreterivelmente necessário um sistema de transportes.

Essa nova morfologia caracteriza-se pela expansão do
tecido urbano, de forma intensa, mas descontínua. Os
espaços urbanos se redefinem. Ao invés de aglomerações
urbanas que designam contiguidade e adensamento
populacional, de infraestruturas e equipamentos, produzem-
se largas tramas urbanas que se redefinem por uma
estruturação polinucleada, interna e externamente
articulada por amplos sistemas de transporte e
comunicação (SPÓSITO, 2001, p.85).

As consequências desse processo são as novas expressões da centralidade, uma vez que atividades que tradicionalmente localizavam-se no centro da cidade passam a localizar-se distribuídas em diferentes setores do tecido urbano. Desta forma, o tecido urbano torna-se polinucleado, com pontos expressivos de aglomerações em diferentes setores causando transformações expressivas em sua forma urbana e, também, refletindo na segregação socioespacial.

O turismo em suas ações no território através de empreendimentos como condomínios, casas de veraneios, restaurantes, parques temáticos, e outros, produz aglomerados exóticos no tecido urbano, que têm uma interação limitada com a realidade local, de modo favorecer a segregação socioespacial.

(...) não são poucos os casos, em território nacional, de empreendimentos alheios aos seus entornos, do ponto de vista de alguma possível integração sociocultural entre turistas que frequentam esses empreendimentos e populações locais (CRUZ, 2003, p.11).

Acerca disso, Sabatini in Oliveira (2001) contribui ao afirmar que as cidades passam por transformações em sua forma urbana, relacionadas com a própria segregação social do espaço. Para o referido autor, há três pontos que explicitam as mudanças na forma das cidades:

a) Descentralização da estrutura urbana em subcentros comerciais, de escritórios e produtivos;

b) A explosão da mancha urbana sobre a região circundante, com base em uma série de desenvolvimentos isolados que ficam 
conectados entre si e com a cidade através de estradas e outras formas de comunicação;

c) Novas formas de segregação social do espaço. Os condomínios fechados - ou gated communities - constituem uma modalidade muito difundida, mas também são importantes os grandes projetos imobiliários multifuncionais na periferia ou na região próxima às cidades. Os condomínios podem ser de baixa densidade ou corresponder à proliferação de formas de ocupação residencial de rendas altas e médias em áreas rurais das cidades, em geral fora das normas urbanas - é o aparecimento da cidade informal dos ricos (SABATINI apud OLIVEIRA, 2001, p. 168).

Essas mudanças espaciais na forma da cidade mantém algo significativo: a estratificação urbana, de modo que a segregação é uma de suas formalizações ou manifestações. Isso é verificado na localização das novas centralidades e nas características socioeconômicas dos frequentadores dos diferentes lugares, como shoppings-centers, ruas comerciais do centro tradicional, e os próprios lugares turísticos construídos para os turistas.

Enfim, a morfologia urbana a partir das novas centralidades, ou seja, esse mosaico com suas diferenças expressivas socioespaciais, explicita a desigualdade que também merece ser compreendida através de estudos da questão da segregação e exclusão espacial urbana, a partir da influência do turismo.

\section{Considerações finais}

Os pontos teóricos apresentados neste ensaio sugerem a geografia urbana como sustentação aos estudos de turismo, tangendo as questões referentes à morfologia urbana, novas centralidades e até mesmo à segregação socioespacial. Neste sentido, as ideias e referências expostas constituem possibilidades de entendimentos para a questão do turismo como elemento urbanizador.

Para o turismo, essa discussão faz-se pertinente, uma vez que, em sua dinâmica, o mesmo consome o espaço urbano atuando em sua (re)produção, e consequentemente alterando o tecido urbano. Para tanto, é essencial ao turismo urbano buscar a compreensão da estruturação espacial urbana e suas variáveis. Nesta perspectiva, o entendimento das novas centralidades urbanas passa pela interdependência entre dinâmicas que envolvem a estruturação interna das cidades, como a nova localização dos equipamentos de comércio e de serviços, dentre os quais os turísticos.

A análise das especificidades do processo de redefinição das centralidades nas localidades turísticas, em suas dimensões e localizações, favorecerá a gestão do território urbano, ou seja, o planejamento do turismo. Assim, reflexões e pesquisas dessa ordem colaboram na gestão urbana das cidades turísticas, direcionando o desenvolvimento urbano de modo a 
considerar as mudanças socioespaciais que permeiam as novas centralidades.

\section{Referências bibliográficas}

CARLOS, A.F.A. O consumo do espaço. In: CARLOS, A.F.A. (org.). Novos caminhos da geografia. São Paulo: Contexto, 2002. p. 173-186.

CORIOLANO, L.N.M.T. Do local ao global: o turismo litorâneo cearense. Campinas: Papirus, 1998.

CORRÊA, R.L. O espaço urbano. São Paulo: Ática, 1995.

CRUZ, R.C.A. Os pseudo-lugares do turismo. In: CRUZ, R.C.A. Geografia do Turismo: de lugares a pseudo-lugares. São Paulo: Roca, 2007.

CRUZ, R.C.A. Introdução a Geografia do Turismo. Rio de Janeiro: Roca, 2003.

GOTTDIENER, M. A produção social do espaço urbano. Trad. Geraldo Gerson de Souza. São Paulo: Editora da Universidade de São Paulo, 1993.

KNAFOU, R. Turismo e território: por uma abordagem cientifica do turismo. In: RODRIGUES, A.B. (org.) Turismo e Geografia: reflexões teóricas e enfoques regionais. São Paulo: HUCITEC,1996, p.62-74.

LUCHIARI, M.T.D.P. Urbanização turística: um novo nexo entre o lugar e o mundo. In: LIMA, L.C. (org.). Da cidade ao campo: a diversidade do saber fazer turístico. Fortaleza: UECE, 1998, p.15-29.

SABATINI, F. Transformação urbana e dialética entre integração e exclusão social: reflexão sobre as cidades latino-americanas e o caso de Santiago do Chile. In: OLIVEIRA, M.C. (org.). Demografia da exclusão social: termos e abordagens. Campinas: Editora da Unicamp, Nepo, 2001.

SILVA, A.F.C.; FERREIRA, A.L. Para além do muro alto: "turismo imobiliário" e novas configurações sócio-espaciais na Região Metropolitana de Natal/RN/Brasil. In: VALENÇA, M.M.; CAVALCANTE, G.M. (orgs.). Globalização e marginalidade. Natal: EDUFRN, 2007.

SPÓSITO, M.E.B. A urbanização da sociedade: reflexões para um debate sobre as novas formas espaciais. In: O espaço no fim do século - a nova raridade. São Paulo: Contexto, 2001, p.83-99.

SPOSITO, M.E.B. Descontinuidades territoriais e novas morfologías urbanas no Estado de São Paulo. In: REIS, N.G.; TANAKA, M.S.; PORTAS, N. (coord.). Dispersão urbana: diálogo sobre pesquisas. Brasil-Europa. São Paulo: FAU-USP, 2007. 
Wilson Martins Lopes Junior: Universidade Federal Fluminense, Angra dos Reis, RJ, Brasil.

E-mail:wmlopesjunior@id.uff.br

Link para o currículo Lattes: http://lattes.cnpq.br/9213724832027329

Data de submissão: 13 de março de 2013

Data de recebimento de correções: 27 de setembro de 2013

Data do aceite: 25 de janeiro de 2014

Avaliado anonimamente 